\title{
SOCIAL MEDIA MARKETING NAS BIBLIOTECAS ACADÉMICAS PORTUGUESAS
}

\begin{abstract}
Resumo: Apresentam-se as perceções dos profissionais da informação das bibliotecas académicas portuguesas face à adoção do conceito social media marketing. Os resultados foram obtidos, através da aplicação de um questionário online à Rede de Informação do Instituto Nacional de Estatística em Bibliotecas do Ensino Superior (Portugal). Conclui-se que apesar dos profissionais da informação reconhecerem o valor da participação das bibliotecas académicas na web social e da sua utilização visando o marketing, ainda são poucas as organizações que apresentam uma participação nas plataformas sociais, em concreto no facebook, com um ritmo de publicação regular, com regras de normas e estilos de utilização e que procedem à sua monitorização e avaliação. Conclui-se também que à estratégia de marketing carecem estudos de perfis dos utilizadores, incluindo a análise dos respetivos comportamentos informacionais, face a este contexto que se impõe na web social.
\end{abstract}

Palavras-chave: Social media marketing.Profissionais da informação. Bibliotecas académicas. Portugal.
Maria Armanda Salgado ${ }^{1}$ Doutora em Ciências da Informação e da Documentação pela Universidade de Évora (Portugal). Investigadora integrada do Centro Interdisciplinar de História, Culturas e Sociedades, pela Universidade de Évora, Portugal. salgadoarmanda@gmail.com

Ana Reyes Pacios Doctora en Historia del Arte por la Universidad de León (1993). Profesora del

Departamento de Biblioteconomía y Documentación de la Universidad Carlos III de Madrid, Espanha. areyes@bib.uc3m.es

\section{SOCIAL MEDIA MARKETING IN PORTUGUESE ACADEMIC LIBRARIES}

\begin{abstract}
The perceptions of 'social media marketing' of information professionals in higher education libraries are presented. Data was gathered through an online questionnaire, to the Information Network of Higher Education Libraries of the National Institute of Statistics (Portugal). Results show that even though information professionals acknowledge the value for higher education libraries of participating in the social web, and its use in marketing, there are still few institutions participating regularly in social media platforms, particularly in facebook, and carrying out monitoring and evaluation activities. We also conclude that the marketing strategy lacks the study of user profiles, including the analysis of their information behaviour when facing the present context of social web.
\end{abstract}

Keywords: Social media marketing. Information professionals. Academic libraries. Portugal.

\footnotetext{
${ }^{1}$ Trabalho desenvolvido no âmbito de: UID/HIS/00057/2013 (POCI-01-0145-FEDER-007702), FCT/Portugal, COMPETE, FEDER, Portugal 2020.
} 


\section{INTRODUÇÃO}

Se a abordagem do conceito de marketing no âmbito das bibliotecas académicas portuguesas ainda causa alguma distância em termos da sua aplicabilidade, mais ceticismo causa a compreensão do valor e a aplicabilidade do conceito de social media marketing. Habitualmente apontam-se como principais motivos para esse distanciamento, não só o facto de persistir uma relação direta do conceito com as organizações com fins lucrativos, mas também o estigma de estar confinado à publicidade e tão só. Já no que diz respeito à dúvida quanto à participação na web social, os argumentos comummente apontados pelos profissionais da informação prendem-se, tanto com o facto de não servir os propósitos da biblioteca (Neo \& Calvert, 2012), como em apresentar fragilidades quer ao nível da irregularidade na publicação nas redes sociais, quer ao nível da ausência de experiências satisfatórias de aprendizagem para os respetivos membros (Gerolimos, 2013), assim como ausência de tempo para dedicação à web social; ausência de competências em termos de usabilidade da web social e dificuldade em demonstrar o ROI - Return On Investement para stakeholders (González Fernández-Villavicencio, 2014).

Assim sendo, este estudo pretende analisar as perceções dos profissionais da informação face à implementação ou utilização do conceito de social media marketing nas bibliotecas académicas, apesar de se reconhecer os dos desafios que lhe estão inerentes, de âmbito tecnológico, económico, político educativo e social e que exigirão ao profissional da informação uma atualização em termos profissionais regular, a par com a capacidade e a predisposição para a implementação de um processo constante e consistente de escuta, de participação e de cocriação com os utilizadores (Gutacker, 2012).

$\mathrm{Na}$ verdade, social media marketing ou marketing digital são o mesmo conceito (González Fernández-Villavicencio, 2013), porque incluem a web social na implementação de uma filosofia de marketing na biblioteca académica: " using social media libraries can engage with their clienteles and enable them to participate in the production of library products" (Khan \& Bhatti, 2012, p. 4). Consequentemente, a colaboração será a nova fonte de inovação, ganhando o conceito novos contornos, aspirando ser movido por valores e atingir o indivíduo na sua essência: o designado marketing 3.0 (Kotler et al., 2011).

Tendo em conta os conceitos relativos à filosofia de marketing que aqui se apresenta, decorreram as questões seguintes e que justificaram a investigação: 
- Como percecionam os profissionais da informação o social media marketing?

- Qual o valor que se encontra associado a este conceito?

- Quais as redes sociais eleitas para comunicar com os utilizadores e quais as motivações para a sua utilização?

- Qual a sua atividade na web social?

\section{SOCIAL MEDIA MAKETING NAS BIBLIOTECAS ACADÉMICAS PORTUGUESAS}

O profissional da informação pode argumentar que as relações com os utilizadores sempre foram uma prioridade, mas o que está a ser oferecido pela era digital, e em concreto pela web social, é uma oportunidade para torná-las mais rápidas e passíveis de propagação e de comentários.

É pois neste contexto que a web social assume um papel de relevo no âmbito da era digital, dando origem ao termo social media marketing, isto é, toda a divulgação e promoção realizada através dos social media. O que no caso das bibliotecas académicas corresponderá à divulgação dos serviços, atividades, recursos, notícias e respetiva marca, através da web social.

Na literatura, o conceito de marketing digital ou social media marketing assume várias denominações: "cibermarketing", "comunicação e marketing online", "webmarketing", "marketing na internet", "marketing interativo" termos esses que apresentam como denominador comum a função de gerar negócios em ambiente digital (Rubleski, 2009), encontrando-se ancorada a relação com o cliente no diálogo. Na verdade, com o social media marketing não só se fomenta o marketing Business to Consumer (B2C), mas também um marketing interativo e relacional, que aposta nas relações a longo prazo, tendo em vista a satisfação e consequente fidelização de clientes. Surge, assim, um novo conjunto de variáveis de marketing adequadas ao ambiente digital: e-product, e-place, e-price, e-promotion (Saéz, 2002), merecendo uma abordagem apropriada a este ambiente, com impactos significativos em cada um dos elementos (Carrera, 2012). A tecnologia é a marca diferenciadora entre o marketing clássico e o da nova era, tendo repercussões igualmente nas bibliotecas: "Access via digital television is likely to be more comfortable option than via home computers for many segments of the public libraries. Libraries must be seen to be credible information 
purveyors, accessible in the same ways as banques and shops, part of the everyday fabric of life" (Saéz, 2002, p.141).

Da mesma forma que as variáveis de marketing se adaptam, também o plano de marketing sofre um ajuste, adequado ao meio digital (Saéz, 2002). Um bom plano de marketing da biblioteca não é suficiente. Na verdade, é necessário contemplar o alinhamento das 'iniciativas 2.0' com o plano de marketing desenvolvido pela biblioteca (Rodríguez Fernández, 2011). Ainda o mesmo autor apela para a necessidade das bibliotecas procederem a uma gestão de projetos de social media, devendo disponibilizar um conteúdo adequado e legal, ou seja, que seja capaz de atender aos requisitos de propriedade intelectual, com licenças de documentação do tipo Copyleft ou Creative Commons e linhas orientadoras, em concreto "Guias de uso e estilo" tendo em vista a normalização da presença e usabilidade das redes sociais pelas bibliotecas.

Só a inclusão da web social no marketing possibilita estabelecer uma comunicação mais efetiva porque tem em conta o processo de escuta, participação e avaliação da interação neste ambiente digital, possibilitando que utilizadores passem de consumidores a produtores. $\mathrm{Na}$ verdade, as redes sociais permitem que os indivíduos falem sobre as instituições em termos do seu desempenho funcional e social (Kotler et al., 2011). É neste contexto que a web social assume relevo para o processo de criação de valor, surgindo assim o conceito de marketing 3.0 como uma mais-valia ao termo social media marketing. Na verdade, a aplicação do marketing 3.0 aspira agregar mais valor aos serviços e indivíduos, atingindo os indivíduos na sua essência, com recurso à tecnologia da nova vaga: os social media. Com o marketing 3.0, o conceito eleva-se para a arena das aspirações, dos valores e do espírito humano (Kotler et al., 2011) (Tabela 1).

Tabela 1: Proposta de implementação de social media marketing na biblioteca académica

\begin{tabular}{|l|l|}
\hline \multicolumn{2}{|c|}{ Social media marketing na biblioteca académica } \\
\hline Para quê? & $\begin{array}{l}\text { Fomentar a interação, colaboração e cocriação } \\
\text { Receber } \text { feed-back, "retro-alimentar" }\end{array}$ \\
\hline $\begin{array}{l}\text { Como? } \\
\text { - Tecnologia } \\
\text { - Valores }\end{array}$ & $\begin{array}{l}\text { Tecnologia de nova vaga: redes sociais } \\
\text { Funcional, emocional e espiritual }\end{array}$ \\
\hline Para quem? & $\begin{array}{l}\text { Stakeholders: colaboradores, utilizadores, tutela e qualquer indivíduo que } \\
\text { mantenha uma relação com a biblioteca }\end{array}$ \\
\hline Quando? & Continuamente \\
\hline Porquê? & Criar valor para o utilizador e agregar mais valor para a biblioteca \\
\hline
\end{tabular}

Fonte: elaboração própria 
Facto é que o marketing "one to many", marketing de massas, deu lugar a um outro pressuposto, isto é, ao marketing "one to few", sendo que a internet é a responsável pela alteração do padrão ao nível da comunicação, em que a palavra de ordem é o relacionamento, dando lugar ao marketing "one to one" (Marques, 2012, p. 31). A tecnologia alterou a forma como se processa e gere o relacionamento com todos os stakeholders, não ficando as bibliotecas imunes: "Cyber-driven libraries and information services will be very different organizations as the digital, interactive information environment changes the way in which management and staff relate to each other, to suppliers, to distributors, to users and to clients" (Saéz, 2002, p. 137).

Sendo o social media marketing um marketing cada vez mais direcionado para o indivíduo, as bibliotecas académicas têm que se adaptar a esta nova realidade. São várias as vantagens da adoção do social media marketing: interativo; analítico (baseado em métricas, através de bases de dados); flexível, sem custos, proporcionando a visibilidade e promoção da marca (Rubleski, 2009; Carrera, 2012).

Através dos social media, os indivíduos podem trocar conteúdos diversos: filmes, músicas, opiniões, notícias, fotos (Saéz, 2002), através de plataformas da web 2.0, tal como foi definida por O'Reilly (2005). Assim, se para este autor a mudança para a web 2.0 passa pelo entendimento da internet como uma plataforma, isto é, como uma tecnologia, que recorre a aplicativos, que se tornam sucessivamente melhores, pelo uso que os internautas dela fazem, pois há um aproveitamento da inteligência coletiva, já para Torres (2009) o conceito é encarado como um fenómeno comportamental na internet. Trata-se, assim, de um termo criado com fins de marketing e não o anúncio de uma tecnologia (Oliveira, 2011). Esta divergência relativa ao entendimento da noção é importante para demonstrar que o centro desse fenómeno está ligado ao modelo de consumo e não a uma tecnologia. Daí a importância de estudos comportamentais e da compreensão da relação dos clientes com os media, utilizadores e a biblioteca, sobretudo através do uso que todos fazem das redes sociais (Adolpho, 2012).

Com efeito, a web 2.0, enquanto plataforma social, permite novas formas de interação entre os utilizadores e destes com a própria tecnologia, fomentando, quer a criação de conteúdos, quer a sua partilha de forma colaborativa (Santos \& Andrade, 2010; Potter, 2012). 
No entanto, para que tal interação se efetive e atinja o alcance e envolvimento esperado, a biblioteca deverá auscultar os utilizadores e optar por disponibilizar nos serviços os social media mais utilizados pelo seu público-alvo, tendo em conta questões como, a) estudos prévios sobre recursos económicos; b) estudos sobre recursos humanos; e, c) estudos sobre recursos tecnológicos antes da sua implementação (Santos \& Andrade, 2010; Gutacker, 2012). De qualquer forma, só a participação da biblioteca académica em diferentes plataformas sociais, dará corpo a um efectivo projeto comunicacional na web social.

Como em Portugal o facebook é a rede social com mais utilizadores, pois segundo a SocialBaker verifica-se desde 2009 (895,720) a 2013 (4.713,400), um aumento do número de perfis, motivo pelo qual se selecionou esta plataforma para realizar o estudo.

Foi também a partir de 2009 que, em Portugal, a publicação sobre este tema, no âmbito das Ciências da Informação, começou a surgir. Estes trabalhos, de uma forma geral, apresentam as redes sociais como uma oportunidade para as bibliotecas ganharem visibilidade externa e efetivarem uma comunicação mais próxima com o público-alvo (Leitão, 2010; Alvim, 2010; Santos, 2011). A verdade é que embora não se aborde nestes estudos, a questão da web social, o conceito de marketing e consequentes temas periféricos tais como: avaliação, qualidade e satisfação de cliente, têm sido alvo de investigação, em particular, no contexto das bibliotecas públicas portuguesas (Pinto, 2007; Marques, 2012).

\section{MÉTODO}

Este trabalho apresenta como objetivo geral analisar as perceções dos profissionais da informação face à implementação ou utilização do social media marketing nas bibliotecas académicas portuguesas. Decorrentes deste objetivo surgem os seguintes objetivos específicos:

- Conhecer o valor que está associado ao conceito;

- Verificar qual/quais a(s) rede(s) social(ais) eleita(s) para a comunicação e motivações para o seu uso;

- Analisar a atividade na web social.

A metodologia utilizada consistiu na aplicação de um questionário. Este questionário assumiu a forma eletrónica, tendo sido disponibilizado através do GoogleDocs, aplicação disponível pelo Google que apresenta um conjunto de templates e de opções de formulação de 
perguntas adequadas à construção do questionário e simultaneamente apelativas ao nível da apresentação. Encontraram-se online durante três meses, de março a maio de 2013 nas páginas do facebook ou blogs das bibliotecas, tendo sido igualmente pedida a colaboração dos bibliotecários responsáveis, no sentido de enviarem o link, via email, para as respetivas mailing lists, com o intuito de obter o número máximo de respostas.

Foi, na verdade, a ferramenta encontrada para recolher dados sobre um universo relativamente abrangente e disperso geograficamente, com custos reduzidos, além do mais o anonimato e a confidencialidade foram assegurados.

O universo estudado foi, assim, de âmbito nacional, integrando um total de 31 (trinta e uma) bibliotecas de Ensino Superior (universidades e institutos politécnicos). Com efeito, na ausência de uma rede de bibliotecas académicas portuguesas, optou-se por aplicar o questionário às bibliotecas do Ensino Superior que integram a rede de informação do Instituto Nacional de Estatística (INE).

O desenho do questionário obedeceu a uma estrutura eclética, pois foram colocadas questões fechadas e abertas, procurando retirar-se partido das vantagens e desvantagens que ambos os tipos de perguntas apresentam.

O questionário encontra-se subdividido em seis grandes itens:

1- Perfil do respondente: possibilitando recolher informação relativa ao tipo de respondente: género; faixa etária, cargo e biblioteca académica na qual exerce a sua profissão.

2- Uso frequente da biblioteca: possibilitando recolher informação sobre a frequência presencial ou em ambiente digital e perceber quais as ferramentas da web utilizadas para divulgar os recursos e serviços da biblioteca.

3- Comunicação e marketing: apresenta-se como um dos tópicos que se encontra explorado em profundidade, incluindo, por isso um número maior de questões, dado que pretende obter informação sobre a forma como a biblioteca implementa a estratégia de comunicação com o seu público-alvo, colocando o enfoque na eventual importância que ofacebook pode assumir nessa mesma estratégia.

4- Relação com o profissional da informação: é outro dos tópicos com importância relevante, porque pretende perceber a forma como os profissionais percecionam a relação comunicacional com os utilizadores e se essa relação apresenta como 
denominador comum a credibilidade, a participação e o entusiasmo. Possibilita igualmente perceber qual a importância da formação em marketing.

5- Formação: pretende auscultar qual a perceção da importância da divulgação de oferta formativa quer a nível presencial, quer em ambiente digital, nomeadamente através das redes sociais, percebendo se lhe é atribuída vantagens.

6- Perceção: as questões colocadas esperam por um lado averiguar qual o papel de profissionais da informação enquanto marketeers da biblioteca e, por outro lado, são colocadas questões abertas com o intuito de auscultar os respondentes, sobre a forma de fomentar o diálogo entre profissionais e público-alvo.

Atribuiu-se ao questionário o título: A good Facebook user, a better marketeer of your library!, cujos resultados responderam na íntegra aos objetivos propostos e que, na sua essência, pretendiam explorar três ideias fundamentais:

1) utilização do facebook em prol do social media marketing;

2) motivações dos profissionais de informação na utilização do facebook;

3) assunção do papel de marketeer.

Segue-se a caracterização da amostra em termos de taxa de resposta ao questionário e perfil dos respondentes.

Obtiveram-se respostas de um total de 19 profissionais, dado ter ocorrido, nalguns casos mais do que uma resposta proveniente da mesma biblioteca. No fundo foram obtidas respostas de 15 bibliotecas académicas, o que perfaz uma taxa de resposta de $63 \%$ em relação ao universo das bibliotecas académicas. 
Tabela 2: Respostas por Instituição de Ensino Superior com as respetivas taxas de resposta

\begin{tabular}{|l|r|r|}
\hline \multicolumn{1}{|c|}{ Instituições } & Frequência & \% \\
\hline Escola Superior de Enfermagem do Porto (Biblioteca) & 1 & 5,3 \\
\hline Instituto Politécnico da Guarda (Biblioteca central) & 1 & 5,3 \\
\hline Instituto Politécnico de Beja (Biblioteca) & 2 & 10,5 \\
\hline Instituto Politécnico de Bragança (Biblioteca da Escola Superior Agrária) & 1 & 5,3 \\
\hline Instituto Politécnico de Castelo Branco (Biblioteca da Escola Superior de Tecnologia & 1 & 5,3 \\
\hline $\begin{array}{l}\text { Instituto Politécnico de Leiria (Serviços de Documentação da Escola Superior de } \\
\text { Tecnologia e Gestão) }\end{array}$ & 3 & 15,8 \\
\hline Instituto Politécnico de Portalegre (Biblioteca da Escola Superior de Tecnologia e Gestão) & 1 & 5,3 \\
\hline Instituto Politécnico de Santarém (Biblioteca da Escola Superior de Gestão) & 1 & 5,3 \\
\hline Instituto Português de Administração de Marketing - Lisboa & 2 & 10,5 \\
\hline Instituto Superior da Maia (Biblioteca) & 1 & 5,3 \\
\hline Universidade de Aveiro (Serviços de Biblioteca, Informação Documental e Museologia) & 1 & 5,3 \\
\hline Universidade de Coimbra (Biblioteca geral) & 1 & 5,3 \\
\hline Universidade de Évora (Biblioteca geral) & 1 & 5,3 \\
\hline Universidade do Algarve (Biblioteca central) & 1 & 5,3 \\
\hline Universidade do Porto (Serviços de Documentação e de Sistemas de Informação da & 1 & 5,3 \\
\hline Faculdade de Letras) & 19 & 100 \\
\hline Total & \\
\hline
\end{tabular}

Fonte: Elaboração própria.

$\mathrm{Na}$ amostra, quase todos os respondentes são profissionais da informação (95\%) com exceção de apenas um elemento que desempenha outro cargo, o de diretor (5\%).

Quanto ao perfil, relativamente ao género, $84 \%$ são mulheres e $16 \%$ são homens. No que se refere à faixa etária, $16 \%$ têm entre 25-34 anos, 31\% apresentam entre 35-44 anos e $53 \%$ integram o grupo com idades compreendidas entre 45 a 54 anos.

\section{DISCUSSÃO E RESULTADOS}

Todos os inquiridos responderam afirmativamente relativamente ao facto da biblioteca proceder à divulgação dos serviços, recursos e atividades. Expõem-se, em seguida, os resultados das respostas segundo o tipo de informação proveniente do questionário:

a) Canais utilizados para a divulgação 
Relativamente aos canais utilizados para divulgação do serviço, os resultados foram os seguintes:

Na amostra, 84\% recebem divulgação "Presencial, pelo(s) técnico(s)/bibliotecário(s)"; 79\% indicam "Correio eletrónico"; 58\% utilizam "Visitas guiadas à biblioteca"; 53\% assinalam as "Redes sociais"; $47 \%$ utilizam "Folhetos"; $31 \%$ referem "Visitas à sala de aula" e $11 \%$ utilizam "SMS" (Fig. 1).

Fig. 1: Canais utilizados pela biblioteca para dar a conhecer a sua atividade

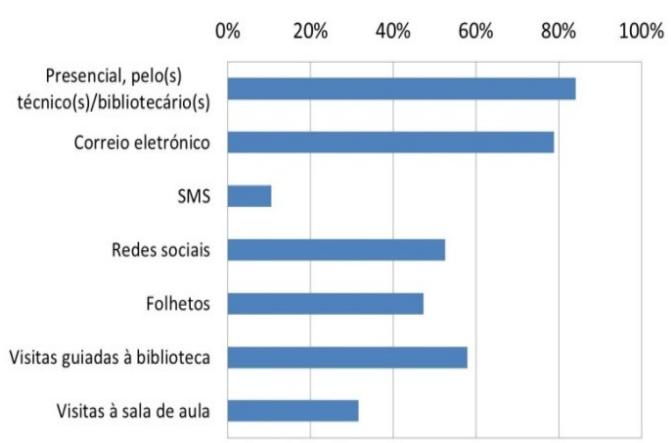

Fonte: Elaboração própria.

Relativamente à comunicação para o exterior, 53\% afirmam ter conhecimento da divulgação e promoção da biblioteca em meios de comunicação exteriores à instituição de Ensino Superior e 47\% não ter conhecimento.

b) Facebook canal de comunicação preferido

As respostas e afirmações dos profissionais de informação evidenciaram a importância do facebook, enquanto ferramenta da web 2.0 como responsável por agilizar a comunicação, reforçar o diálogo com utilizadores e, consequentemente, os relacionamentos entre a biblioteca académica e o seu público-alvo.

Quando questionados acerca da presença no facebook, (53\%) responderam que a biblioteca não tem página e $47 \%$ confirmaram a existência desta. Dos respondentes que consideraram que a biblioteca tinha página no facebook, $90 \%$ referem que as bibliotecas disponibilizam "Notícias", "Serviços", "Recursos", "Eventos” e "Formação"; 67\% 
"Comemoração de dias festivos" e "Horário"; 57\% "Newsletter"; 44\% "Tutoriais" e que 33\% disponibilizam "Humor" e "Vídeos" (Fig. 2). Apenas 33\% são administradores da página.

Fig. 2: Conteúdos disponibilizados no facebook

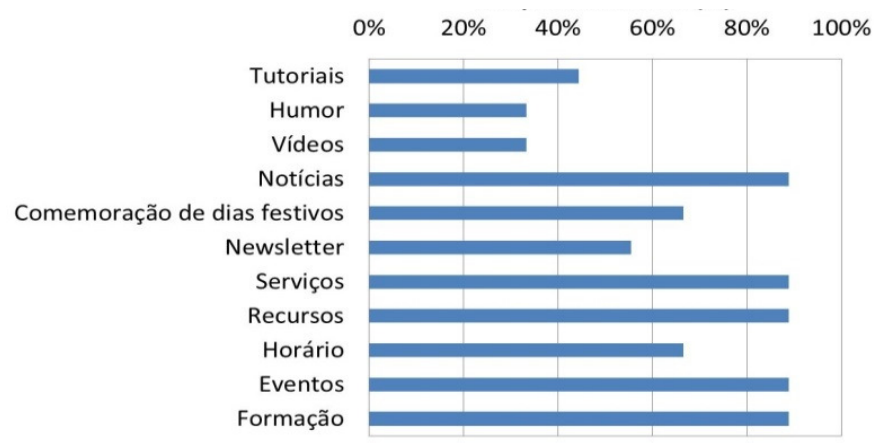

Fonte: Elaboração própria

No que diz respeito ao grau atribuído à atualização e interesse da página do facebook," e 56\% respondem "atual e interessante" e $44 \%$ consideram "muito atual e interessante.

Dos respondentes que assinalaram que a biblioteca tinha página no facebook, $89 \%$ consideram que a biblioteca faz uso do facebook para comunicar de forma regular com os utilizadores e $11 \%$ (um elemento) não sabe.

Os profissionais que respondem que a biblioteca tem página no facebook, quando a consultam, 37\% "coloca gosto" e "partilha a publicação", 13\% (um elemento) "comenta a publicação" e também $13 \%$ (um elemento) nada faz.

Dos inquiridos que respondem que a biblioteca tem página no facebook, $45 \%$ têm por hábito publicar na página, 33\% não publicam e 22\% publicam raramente.

Quanto à tipologia de publicações, 75\% (3 elementos) divulgam conteúdos de "Serviços" e "Eventos"; 50\% (2 elementos) divulgam conteúdos relativos a "Tutoriais", "Notícias", "Recursos" e "Formação"; 25\% (1 elemento) divulgam conteúdos de "Comemoração de dias festivos", não sendo assinalados os conteúdos "Humor", "Vídeos", "Newsletter" e "Horários".

$\mathrm{Na}$ amostra, 59\% consideram importante a biblioteca ter uma página no facebook, $29 \%$ respondem "talvez" e $12 \%$ não consideram importante.

No que se refere à monitorização, 71\% concordam com a monitorização e a avaliação das páginas do facebook das bibliotecas, sendo conferida mais importância aos itens "Melhora 
a visibilidade da biblioteca " e "Auxilia a definir objetivos mais específicos e exequíveis em termos de comunicação".

c) Reconhecimento da importância da formação em marketing para a estratégia de comunicação adequada às redes sociais

Apesar de na Europa, desde finais da década de 80, a formação em marketing ser considerada fundamental no âmbito dos cursos de formação de Ensino Superior, em Portugal, apenas em 2006, se equacionou a integração deste conteúdo programático (Alves et al., 2006). Na verdade, já em 2005, o marketing foi considerado conteúdo prioritário na formação dos futuros profissionais da informação europeus (Kajeberg \& Lorring, 2005). Hoje, perante o uso massivo das redes sociais, converteu-se numa ferramenta indispensável para o desenvolvimento da identidade digital da biblioteca. É, por isso, urgente a incorporação deste conteúdo não só ao nível do ensino, mas também na prática profissional, de forma a assegurar uma boa estratégia de comunicação entre a organização e os utilizadores.

Os próprios profissionais da informação corroboram esta opinião, tendo em contas as respostas dadas. $\mathrm{Na}$ amostra, 53\% consideram importante que o profissional da informação tenha formação em marketing, sendo a importância média bastante elevada para todos os itens, sendo superior para "Contribuir para fomentar o diálogo entre utilizadores" e "Contribuir para a qualidade dos serviços e recursos de informação", seguido de "Contribuição para aumentar o nível de interesse pela biblioteca em geral" e depois de "Contribuir para fomentar o diálogo com o profissional de informação"

Quanto à perceção do papel da biblioteca em termos de marketing, 26\% consideram "muito ativo", $63 \%$ "ativo" e $11 \%$ "passivo".

Os respondentes que se consideram marketeers da biblioteca, através dos social media, 70\% assinalam "Participo nos eventos anunciados"; 50\% "Porque partilho publicações" e "Divulgo a URL da biblioteca através de mailing lists"; 40\% assinalam "Comento publicações"; $30 \%$ indicam "Coloco fotos ou atualizo álbum de fotos"; "Organizo concurso mensal para fãs" e "Envio mensagens a amigos já existentes, para ajudar na promoção da página" (Fig. 3). 
Fig. 3: Ações apontadas pelos profissionais da informação enquanto marketeers 2.0

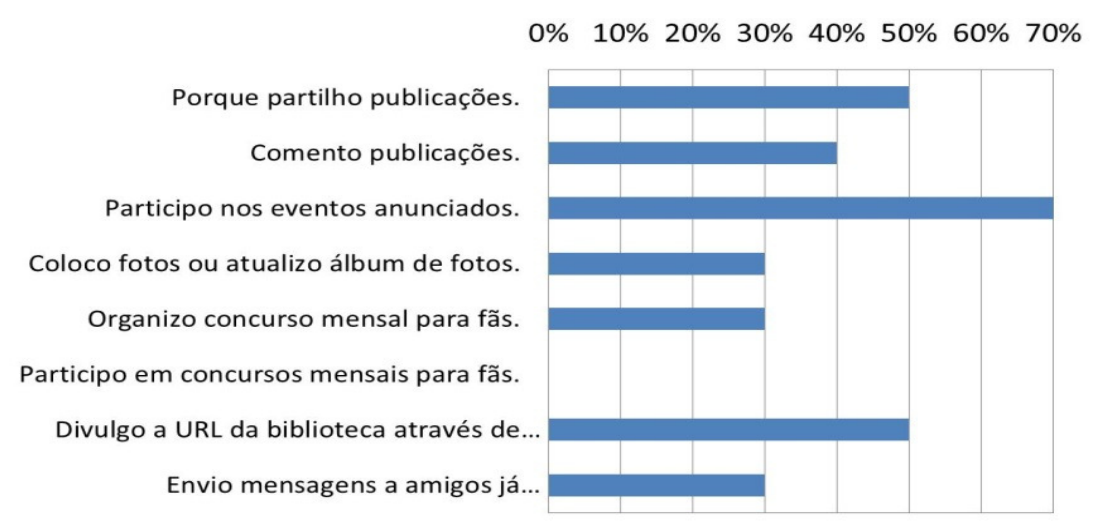

Fonte: Elaboração própria.

d) Reconhecimento do valor do conceito social media marketing

Em termos de reconhecimento do valor da presença nas redes sociais pelos profissionais, as perguntas de resposta aberta dão conta desse reconhecimento a diferentes níveis: potenciador de diálogo; de divulgação; de promoção; e, de inovação:

\section{Afirmação 1}

"O facebook constitui uma forma de contacto privilegiado com os utilizadores da biblioteca."

\section{Afirmação 2}

"Por ser um meio divulgação com muitas potencialidades."

Afirmação 3

"Porque é uma moda e temos que acompanhar esta tendência."

\section{Afirmação 4}

"Promoção do serviço."

A instituição de Ensino Superior ganhará, indiretamente, visibilidade com a existência de mais um canal de comunicação, na medida em que tecnologia e colaboradores estão associados à qualidade e às perceções de valor e, consequentemente, à lealdade destes (Marques, 2012). Mais uma vez, alguns comentários dos profissionais indicam qual a contribuição do facebook, para a projeção da instituição de Ensino Superior, sendo uma ferramenta facilitadora da comunicação entre a comunidade académica:

\section{Afirmação A}


"Dinamização do espaço, do instituto superior a que pertence, dos conteúdos que disponibiliza, e pela aproximação à comunidade estudantil.”

\section{Afirmação $B$}

"Normalmente é mais usado e acedido do que a página da universidade ou biblioteca.

E podia ser uma forma de potenciar o acesso à biblioteca"

\section{Afirmação $C$}

"Facilita a comunicação com a comunidade académica. É uma forma de divulgar tudo o que há disponível na mesma e incentivar os alunos, docentes, funcionários e alunos externos a "usá-la"”.

Apesar de se reconhecerem as vantagens da adopção deste canal de comunicação e respetivo valor, na prática, os profissionais da informação ainda não se encontram a explorar de forma sistemática as potencialidades do facebook. Na verdade, um dos motivos que parece estar na origem do desaproveitamento do facebook, em termos de marketing interno e externo por parte das bibliotecas académicas, prende-se com o facto da maioria dos profissionais de informação não ser administrador da página. O que na prática acarretará repercussões, quer em termos de disponibilização de conteúdos adequados às necessidades informacionais dos utilizadores, quer no que diz respeito à projeção da imagem de marca da biblioteca, tornandoa pouco interessante e desatualizada. De igual forma, a aquisição de formação específica em social media marketing, por parte destes profissionais asseguraria a visibilidade dos serviços e respetiva qualidade junto de todos os stakeholders. A garantia para a certificação da qualidade passaria pela implementação de um conjunto de procedimentos: conceção de um projeto na web social, sustentado por um plano estratégico, norteado por objetivos exequíveis e passíveis de serem mensuráveis, através de indicadores qualitativos e quantitativos, ainda que lhes sejam apontadas algumas fragilidades: "ROI que, como sabemos, no sólo puede ser financiero y en el contexto de la bibliotecas, esa rentabilidade se traduce en un mayor uso de sus productos, servicios y espacios o del impacto de sus bibliotecarios" (González FernándezVillavicencio, 2015).

Por conseguinte, em termos de social media marketing há, ainda, trabalho a ser realizado no âmbito das bibliotecas académicas portuguesas. Neste sentido, é fundamental continuar a estudar perfis e comportamentos informacionais na web social com o intuito de 
perceber futuras tendências em termos de comunicação, integrando-as na estratégia de marketing da organização.

\section{CONCLUSÃO}

Os resultados obtidos através da análise descritiva dos questionários dão conta de dois tipos de percepções: marketing em geral e social media marketing, evidenciando, em concreto, as ações a implementar no âmbito do social media marketing.

Por um lado, permitiram caracterizar o papel do profissional da informação na qualidade de marketeer, pois a maioria dos profissionais inquiridos revê-se nesse papel (53\%), assumindo igualmente que o seu serviço apresenta um papel ativo (63\%) em termos de marketing. Os profissionais reconhecem, ainda, a importância em possuir formação nesta área (53\%), dado não existir um investimento na capacitação de recursos humanos neste domínio. Por outro lado, verifica-se que embora persista uma participação incipiente na web social, assim como uma fraca usabilidade de plataformas sociais constata-se a existência de boas práticas nas bibliotecas académicas portuguesas com perfil no facebook que deverão, contudo, ser reforçadas e melhoradas. Assim, conclui-se que:

a) Facebook é a plataforma social preferencial;

b) Existência da adoção de postura proativa na constante divulgação da página:

c) Identificação de principais ações de participação na web reveladoras de uma atitude 2.0;

d) Regularidade em termos de publicação;

e) Atualização e interesse da página do facebook;

f) Diversificação de conteúdos.

g) Reconhecimento da importância e monitorização e avaliação das páginas do facebook;

h) Estratégia para reconhecer fontes de valor. 


\section{Bibliografia}

ADOLPHO, C. Os 8Ps do marketing digital: o guia estratégico de marketing digital. Alfragide: Texto Editores, 2012.

ALVES et al. A licenciatura em Ciências da Informação e da Documentação da Faculdade de Filosofia de Braga. Cadernos BAD, v.1, 2006. Disponível em:

$<$ http://www.bad.pt/publicacoes/index.php/cadernos/issue/view/21>. Acesso em: 31 março 2014.

ALVIM, L. Da blogosfera ao Facebook: o paradigma da comunicação nas bibliotecas portuguesas. Cadernos BAD, n. 1/2, 2010. Disponível em:

$<$ http://www.bad.pt/publicacoes/index.php/cadernos/article/view/752>. Acesso em: 22 agosto 2014.

CARRERA, F. Marketing digital na versão 2.0: o que não pode ignorar. Lisboa: Edições Sílabo, 2012.

GEROLIMOS, M. Academic libraries on Facebook: an analysis of user comments. D-Lib Magazine, v. 17, n. 11/12, 2013. Disponível em:

$<$ http://www.dlib.org/dlib/november11/gerolimos/11gerolimos.html > . Acesso em: 27 agosto 2014.

GUTACKER, J. M. Marketing the Franklin \& Marshall College Library with social media: a strategic plan. 2012. Disponível em:

<http://jgutacker.info/wordpress1/wp-content/uploads/2014/04/MarketingStrategicPlan.pdf>. Acesso em: 15 agosto 2014.

KAJBERG, L.; LORRING, L. (eds). European Curriculum Reflections on Library and Information Science. Denmark: Royal School of Library and Information Science, 2005. Disponível em: http://www.library.utt.ro/LIS_Bologna.pdf. Acesso em: 29 agosto 2015

KHAN, S. A.; BHATTI, R. Application of social media in marketing of library and information services: a case study from Pakistan. Webology, v. 9, n.1, 2012. Disponível em: $<$ http://www.webology.org/2012/v9n1/a93.html>. Acesso em: 27 agosto 2014.

KOTLER, P. et al. Marketing 3.0: dos produtos e consumidores ao espírito humano. Lisboa: Actual Editora, 2011.

LEITÃO, P. A biblioteca 2.0: oportunidades e desafios para as bibliotecas do século XXI. Cadernos BAD, $n .1 / 2$, 2010. Disponível em: $<$ http://www.bad.pt/publicacoes/index.php/cadernos/article/view/750>. Acesso em: 29 julho 2014.

MARQUES, A. Marketing relacional: como transformar a fidelização de clientes numa vantagem competitiva. Lisboa: Edições Sílabo, 2012. 
MARQUES, M. B. A satisfação do cliente de serviços de informação: as bibliotecas públicas da região centro. 2012. Dissertação (Doutoramento em Ciências Documentais) Faculdade de Letras da Universidade de Coimbra, 2012.

NEO, E.; CALVERT, P. Facebook and the diffusion of innovation in New Zealand public libraries. Journal of Librarianship and Information Science, v. 44, $n$. 4, 2012. Disponível em: < http://lis.sagepub.com/content/early/2012/03/01/0961000611435038>. Acesso em: 29 julho 2014.

OLIVEIRA, L. A. Estratégias digitais de marketing orientadas à performance das instituições. 2011. Disponível em:

<http://bdm.unb.br/bitstream/10483/1674/1/2011_LucasdeAraujoOliveira.pdf>. Acesso em: 6 agosto 2014.

GONZÁLEZ FERNÁNDEZ-VILLAVICENCIO, N. Social media marketing o marketing digital?. 2012. Disponível em:

<http://www.nievesglez.com/2013/03/social-media-marketing-o-marketing.html >. Acesso em: 15 agosto 2014.

GONZÁLEZ FERNÁNDEZ-VILLAVICENCIO, N.¿Cómo perciben los stakeholders (bibliotecarios y usuarios), la intersección biblioteca / web social?. 2014. Disponível em: $<$ http://eprints.rclis.org/23671/1/\%C2\%BFC\%C3\%B3mo\%20perciben\%20los\%20stakeholde rs \%20\%28bibliotecarios\%20y\%20usuarios \%29,\%201a\%20intersecci\%C3\%B3n\%20bibliotec a\%20_\%20web\%20social_.pdf >. Acesso em: 8 setembro 2014.

GONZÁLEZ FERNÁNDEZ-VILLAVICENCIO, N. ROI en medios sociales: campañas de marketing en bibliotecas. El profesional de la información, v. 24, n. 1, 2015. Disponível em: $<$ http://www.elprofesionaldelainformacion.com/contenidos/2015/ene/03.html >. Acesso em: 31 março 2015.

O'REILLY, T. What is Web 2.0: design patterns and bussiness models for the next generation of software. 2005. Disponível em:

<http://oreilly.com/web2/archive/what-is-web-20.html>. Acesso em: 15 agosto 2014.

PINTO, M. L. O marketing nas bibliotecas públicas portuguesas. Évora; Lisboa:

CIDEHUS: Colibri, 2007.

POTTER, N. The library marketing toolkit. London: Facet Publishing, 2012.

RODRÍGUEZ FERNÁNDEZ, O. Community manager: conviértete en experto en "social media". Madrid-ESP: AnayaMultimedia, 2011.

RUBLESCKI, A. Webmarketing e cibercliente: o marketing em tempos de “4Ps+2D's+ 4C's. Bocc-Biblioteca on-line de Ciências da Comunicação, 2009. Disponível em:

$<$ http://www.bocc.ubi.pt/pag/rublescki-anelise-webmarketing-cibercliente.pdf>. Acesso em: 20 junho 2014.

SAÉZ, E. E. Marketing concepts for libraries and information services. London: Facet Publishing, 2002. 
SANTOS, A.; ANDRADE, A. Bibliotecas universitárias portuguesas no universo da web 2.0. Encontros Bibli: revista electrônica de biblioteconomia e ciências da informação, 2010. Disponível em: $<$ https://periodicos.ufsc.br/index.php/eb/article/view/16586/15766>. Acesso em: 14 julho 2014.

SANTOS, A. S. Webmarketing e redes sociais nas bibliotecas. Cadernos BAD, n. 1/2, 2011. Disponível em:

$<$ http://www.bad.pt/publicacoes/index.php/cadernos/article/view/738>. Acesso em: 4 julho 2014.

TORRES, C. A bíblia do marketing digital: tudo o que você queria saber sobre marketing e publicidade na internet e não tinha a quem perguntar. São Paulo: Novatec, 2009. 